\title{
Librarians as the guardian of knowledge
}

Dasapta Erwin Irawan ${ }^{1}$

1 Ins titut Teknologi Bandung

The role of librarians with their close interactions in research ecosystem to guard knowledge within the following activities:

1. to provide open access to knowledge and to make it publicly accessible forever,

2. to maintain the sustainability of knowledge dissemination system, including: funding, human resources, and infrastructure

3. to advocate the democratization of knowledge, including providing explanation, influence research ecosystem and stakeholder to support free knowledge dissemination and to foster all open initiatives so they can grow their interests in developing science. 